\title{
A nomogram for predicting the risk of invasive pulmonary adenocarcinoma for patients with solitary peripheral subsolid nodules
}

\author{
Chenghua Jin, MD, ${ }^{\mathrm{a}, \mathrm{b}}$ Jinlin Cao, MD, ${ }^{\mathrm{a}}$ Yu Cai, MD, ${ }^{\mathrm{c}}$ Lijie Wang, MD, ${ }^{\mathrm{b}}$ Kai Liu, MD, ${ }^{\mathrm{b}}$ Weiyu Shen, MD, \\ and Jian $\mathrm{Hu}, \mathrm{MD}^{\mathrm{a}}$
}

\begin{abstract}
Objective: The subsolid nodule is a common clinical concern. The aim of this study was to construct a nomogram to predict the risk of invasive pulmonary adenocarcinoma in patients with a solitary peripheral subsolid nodule.

Methods: We reviewed the records of 293 patients who had undergone resection of a solitary peripheral subsolid nodule, including the results of pathologic examinations after surgical resection. Clinical parameters and imaging features were analyzed by the use of univariable and multivariable logistic regression analysis. A nomogram to predict the risk of invasive pulmonary adenocarcinoma was constructed and validated with bootstrap resampling.
\end{abstract}

Results: Two hundred seventy-three patients were included for analysis; 35 were diagnosed as benign, 3 as atypical adenomatous hyperplasia, 18 as adenocarcinoma in situ, 58 as minimally invasive adenocarcinoma, and 159 as invasive pulmonary adenocarcinoma. After final regression analysis, the computed tomography attenuation, nodule size, spiculation, signs of vascular convergence, pleural tags, and solid proportion were identified and were entered into the nomogram. The nomogram showed a robust discrimination, with an area under the receiver operating characteristic curve of 0.894 . The calibration curves for the probability of invasive pulmonary adenocarcinoma showed optimal agreement between the probability as predicted by the nomogram and the actual probability.

Conclusions: We developed a nomogram that can predict the risk of invasive pulmonary adenocarcinoma for patients with a solitary peripheral subsolid nodule. Validation by the use of bootstrap resampling revealed optimal discrimination and calibration, indicating that the nomogram may have clinical utility. This model has the potential to assist clinicians in making treatment recommendations. (J Thorac Cardiovasc Surg 2017;153:462-9)

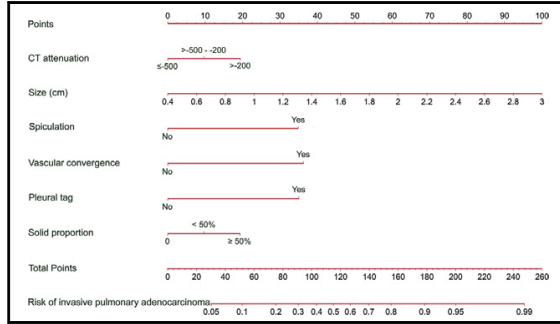

Nomogram predicts risk of invasive pulmonary adenocarcinoma for solitary subsolid nodule.

\section{Central Message}

This study has developed a nomogram that can predict the risk of invasive pulmonary adenocarcinoma for patients with a solitary peripheral subsolid nodule.

\section{Perspective}

The current surgery strategy for preinvasive and invasive pulmonary adenocarcinoma tends to differ, and until now, there has been no effective model to guide surgical management. This nomogram might help clinicians to make individualized predictions of each patient's probability of invasive pulmonary adenocarcinoma and assist clinicians in making treatment recommendations.

See Editorial Commentary page 470.

See Editorial page 460 .
From the a Department of Thoracic Surgery, The First Affiliated Hospital, School of Medicine, Zhejiang University, Hangzhou; and Departments of ${ }^{\mathrm{b}}$ Thoracic Surgery and ${ }^{\mathrm{c}}$ Radiology, Ningbo Medical Center Lihuili Eastern Hospital, Ningbo, Zhejiang, China.

This work was supported by the Key Project of Zhejiang Province Science and Technology Plan, China (2014C03032).

Drs Jin and Cao contributed equally to this article.

Received for publication March 30, 2016; revisions received Sept 29, 2016; accepted for publication Oct 11, 2016; available ahead of print Nov 9, 2016.

Address for reprints: Jian Hu, MD, Department of Thoracic Surgery, The First Affiliated Hospital, School of Medicine, Zhejiang University, 79 Qingchun Rd, Hangzhou, Zhejiang 310003, China (E-mail: hujian_med2@163.com).

$0022-5223 / \$ 36.00$

Copyright (C) 2016 by The American Association for Thoracic Surgery

http://dx.doi.org/10.1016/j.jtcvs.2016.10.019
The pulmonary nodule is defined as a small, focal, and approximately round radiographic opacity, $\leq 3 \mathrm{~cm}$ in diameter, that is surrounded by lung parenchyma. ${ }^{1}$ According to the British Thoracic Society guidelines, pulmonary nodules

Scanning this QR code will take you to the video and appendix for this article. 

Abbreviations and Acronyms
$\mathrm{CT}=$ computed tomography
$\mathrm{HU}=$ Hounsfield units
IPA = invasive pulmonary adenocarcinoma
$\mathrm{SSN}=$ subsolid nodule

are divided into solid and subsolid categories. ${ }^{2}$ The subsolid nodule ( $\mathrm{SSN}$ ) includes pure ground-glass nodules (synonymous with nonsolid nodules) and part-solid nodules in which both solid and ground-glass components are presented. They have attracted increasing attention in recent years as they increasingly are subjected to computed tomography (CT) screening. ${ }^{2,3}$ The optimal management of patients with an SSN is of growing clinical concern, because the most common diagnosis for resected SSNs is lung adenocarcinoma. ${ }^{3,4}$

In 2011, a new pathologic classification proposed that lung adenocarcinoma should be divided into preinvasive and invasive pulmonary adenocarcinoma (IPA) groups. Preinvasive lesions were stratified into atypical adenomatous hyperplasia, adenocarcinoma in situ, and minimally invasive adenocarcinoma. ${ }^{5,6}$ The clinical management of these 2 groups tends to differ: because preinvasive groups have a near- $100 \%$ 5-year survival rate after complete resection, sublobar resection may be acceptable, whereas IPA may be amenable to treatment with the standard lobectomy and the scope of lymph node dissection. ${ }^{4,6}$ Distinguishing between preinvasive and invasive lesions without full histologic sampling, however, is difficult, which limits optimal treatment planning. Therefore, it is necessary to construct an effective preoperative model for predicting the risk of IPA. ${ }^{7}$

The nomogram has been accepted as a reliable tool to create a simple intuitive graph of a statistical predictive model that quantifies the risk of a clinical event. ${ }^{8,9}$ In this study, we aimed to identify the combination of variables that resulted in a highly accurate prediction of IPA in patients with a solitary peripheral SSN. A nomogram for predicting the risk of IPA probability was then constructed to support clinicians in their treatment recommendations.

\section{PATIENTS AND METHODS \\ Patients}

From January 2013 to December 2014, we retrospectively reviewed 293 consecutive patients who underwent surgical resection of a solitary peripheral SSN at the Department of Thoracic Surgery. A peripheral lung nodule was defined as a nodule within the small bronchia of the visceral pleura in the lung parenchyma distal to the tertiary bronchovascular bifurcation. The information retrieved included age, sex, smoking history, family history of lung cancer, preoperative serum carcinoembryonic antigen level, CT features, and pathologic details. Smoking history was defined as smoking at least 100 cigarettes before the interview date. ${ }^{10}$ The normal range of carcinoembryonic antigen is $5 \mathrm{ng} / \mathrm{mL}$ or less; here, the cutoff value level was identified as $2.5 \mathrm{ng} / \mathrm{mL}^{8}$
CT images were obtained by 16-detector-row CT scanners (Brilliance; Philips Medical Systems, Cleveland, $\mathrm{OH}$ ). The lung window level was -600 Hounsfield units (HU) and the width was $1500 \mathrm{HU}$; the mediastinal window level was $30 \mathrm{HU}$ and the width was $400 \mathrm{HU}$. Baseline CT scans of the chest were performed from the thoracic inlet to the middle portion of the kidneys by the use of a 5-mm section thickness; high-resolution CT images were obtained at a section thickness of $1 \mathrm{~mm}$. Radiologic features were reviewed by 2 experienced chest radiologists who were blinded to the patients' clinical and pathologic information. The lesion size, location, shape, margin, interface, internal characteristics, adjacent structure, and CT attenuation value were assessed. The lesion size was defined as the mean of the longest diameter of the entire nodule and its perpendicular diameter. ${ }^{11}$ Vascular convergence was defined as vessels crowding the internal part of the nodule or abnormally angled toward the nodule compared with the normal lung parenchyma. A pleural tag was defined as a linear attenuation extending toward the pleura from the nodule. Spiculation was presented as fibrotic strands radiating into the surrounding lesions (Figure 1). ${ }^{12,13}$ The CT attenuation was calculated with the region-of-interest cursors, which measured the edge of the lesion on the slices containing the region of the entire nodule with the maximum diameter. ${ }^{14}$ The solid proportion was measured as the volume proportion of the solid component in the nodule volume ( $\mathrm{V}$ solid/V nodule). ${ }^{12}$

All of the pathologic specimens were evaluated by 2 experienced lung pathologists (one is an associate senior pathologist whose conclusions were confirmed by a more experienced senior pathologist). The entire specimen was fixed in formalin and embedded in paraffin. Histologic evaluations were conducted by the examination of hematoxylin-eosinstained slides with light microscopy. Adenocarcinomas were classified according to the International Association for the Study of Lung Cancer/ American Thoracic Society/European Respiratory Society classification of lung adenocarcinomas. ${ }^{6}$ This study was performed in accordance with the principles outlined in the Declaration of Helsinki and approved by the ethical committee and the institutional review board.

\section{Statistical Analysis}

The linearity assumption in continuous variables was examined with restricted cubic splines. The associations of the risk of IPA in patients with a solitary peripheral SSN with clinical parameters and imaging features were evaluated by the use of univariable logistic regression analysis. The variables with $P$ values less than 0.1 were entered into the backward regression multivariable analysis to identify the risks for IPA factors. A step-down method was then used to select a subset of the predictors to achieve a relatively parsimonious model with the maximum concordance index and excellent log-likelihood ratio for the final model. ${ }^{15}$ On the basis of the results from the final regression analysis, a nomogram for IPA probability was constructed.

The performance of the nomogram was assessed by discrimination and calibration. ${ }^{16}$ The discriminative ability of the model was determined by the area under the receiver operating characteristic curve, which ranged from 0.5 (no discrimination) to 1 (perfect discrimination). ${ }^{17}$ The calibration of the prediction model was performed by a visual calibration plot comparing the predicted and actual probability of IPA. In addition, the nomogram was subjected to 1000 bootstrap resamples for internal validation to assess their predictive accuracies. ${ }^{18}$ The model development and validation code are displayed in Appendix 1. We also analyzed the classification accuracy in the model based on the following risk strata: low risk $(<5 \%)$, intermediate risk $(5 \%-65 \%)$, and high risk $(>65 \%){ }^{19}$

The statistical analyses and graphics were performed with IBM SPSS 20.0 (SPSS Inc, Armonk, NY) and R 3.1.2 (The R Foundation for Statistical Computing, Vienna, Austria) with the $r m s$ statistical packages. ${ }^{20}$ For all the analyses, $P<.05$ was considered to be statistically significant and all tests were 2-tailed, unless otherwise indicated. 

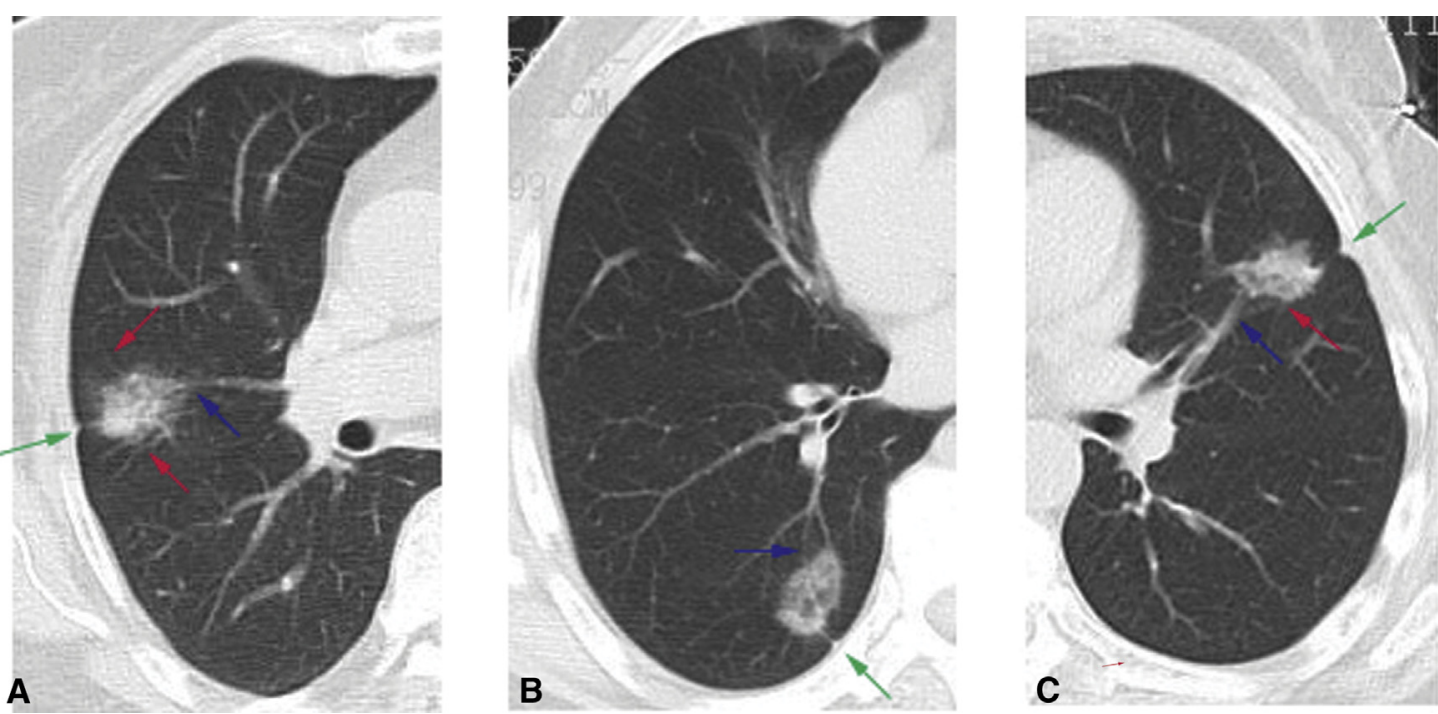

FIGURE 1. Computed tomography image shows vascular convergence (blue arrows), pleural tags (green arrows), and spiculation (red arrows) (A) in right upper lobe of 67-year-old woman, (B) in right lower lobe of 72-year-old man, and (C) in left upper lobe of 61-year-old woman.

\section{RESULTS}

Of the 293 patients in the primary database, 20 patients with a clinical determination of node positive disease were excluded. Node positivity was determined by preoperative endobronchial ultrasound-guided lymph node biopsy. A total of 273 patients were enrolled to develop and validate our predictive nomogram model. The clinical and radiologic characteristics of patients are summarized in Table 1. In addition, all SSNs in both groups had irregular shapes and unclear boundaries. Because there was no obvious statistical significance, the boundaries and shapes of the nodules did not enter into analysis.

\section{Selected Factors for Model}

After univariable analysis, the variables of age, family history of lung cancer, CT attenuation, lesion size, vascular convergence, pleural tag, spiculation, and solid proportion were entered into the multivariable logistic regression analysis. The multivariable analyses demonstrated that the occurrence of IPA was significantly correlated with lesion size $(P<.001)$, spiculation $(P=.004)$, vascular convergence $(P=.034)$, and pleural tag $(P=.005)$; however, age, family history of lung cancer, CT attenuation, and solid proportion were not significant. Based on the excellent concordance index and log-likelihood ratio achieved via step-down selection, CT attenuation and solid proportion also were entered into final regression analysis (Table 2).

\section{Predictive Nomogram for the Probability of IPA}

On the basis of the final regression analysis, a nomogram was constructed that incorporated the 6 significant risk factors for predicting IPA (Figure 2). A total score was calculated with the use of CT attenuation, spiculation, lesion size, vascular convergence, pleural tag, and solid proportion. The value of each of these variables was given a score on the point scale axis. A total score could be easily calculated by adding each single score and, by projecting the total score to the lower total point scale, we were able to estimate the probability of IPA.

\section{Performance of the Nomogram}

Based on the receiver operating characteristic analysis, the nomogram showed a robust discrimination, with an area under the receiver operating characteristic curve of 0.894 ( $95 \%$ confidence interval $0.856-0.932$ ). A calibration curve of the nomogram is presented in Figure 3, which shows that the IPA probabilities predicted by the nomogram agreed well with the actual probabilities. Table 3 shows that the prediction accuracies of our model varied according to the risk cutoff points used to define a positive result. The population prevalence of disease for this population of patients was $58 \%$. The sensitivity and negative predictive values decreased as the risk scores increased, but the specificity and positive predictive values increased.

\section{DISCUSSION}

The clinical management of patients with SSN can be challenging. ${ }^{2,19,21}$ In this study, we created a simple intuitive graph of a statistical predictive model that quantified the risk of IPA and thereby may support clinicians when making treatment recommendations for patients with SSN. We identified 6 factors that were predictive of pathologic IPA, namely CT attenuation, lesion size, spiculation, vascular convergence signs, pleural tag, and solid proportion. Importantly, our nomogram predicts patient-specific probabilities of IPA with optimal discrimination and excellent calibration. The false negative for identifying invasive adenocarcinoma in 
TABLE 1. Patient clinical and radiologic characteristics and univariable analysis of the risk of invasive pulmonary adenocarcinoma in 273 patients with a solitary peripheral subsolid pulmonary nodule

\begin{tabular}{|c|c|c|c|c|c|}
\hline \multirow[b]{2}{*}{ Variables } & \multicolumn{3}{|c|}{ Patients } & \multirow[b]{2}{*}{ OR $(95 \%$ CI $)$} & \multirow[b]{2}{*}{$P$ value } \\
\hline & Total & IPA $(\%)$ & Others $*(\%)$ & & \\
\hline Sex & & & & & .847 \\
\hline Female & 179 & $105(66.0)$ & $74(64.9)$ & Reference & \\
\hline Male & 94 & $54(34.0)$ & $40(35.1)$ & $0.951(0.574-1.578)$ & \\
\hline Age, $y$, mean \pm SD & $59.6 \pm 10.5$ & $62.4 \pm 8.9$ & $55.7 \pm 11.3$ & & $<.001$ \\
\hline$\leq 60$ & 137 & $64(40.3)$ & $73(64.0)$ & Reference & \\
\hline$>60$ & 136 & $95(59.7)$ & $41(36.0)$ & $2.643(1.608-4.343)$ & \\
\hline Nodule location & & & & & .179 \\
\hline Right upper lobe & 106 & $59(37.1)$ & $47(41.2)$ & Reference & \\
\hline Right middle lobe & 19 & $7(4.4)$ & $12(10.5)$ & $1.075(0.537-2.152)$ & .837 \\
\hline Right lower lobe & 47 & $27(17.0)$ & $20(17.5)$ & $0.465(0.170-1.273)$ & .136 \\
\hline Left upper lobe & 73 & $46(28.9)$ & $27(23.7)$ & $1.357(0.737-2.499)$ & .327 \\
\hline Left lower lobe & 28 & 20 (12.6) & $8(7.0)$ & $1.992(0.806-4.923)$ & .136 \\
\hline Smoking history & & & & & .967 \\
\hline No & 208 & $121(76.1)$ & $87(76.3)$ & Reference & \\
\hline Yes & 65 & $38(23.9)$ & $27(23.7)$ & $1.012(0.575-1.781)$ & \\
\hline Family history of lung cancer & & & & & .081 \\
\hline No & 263 & $156(98.1)$ & $107(93.9)$ & Reference & \\
\hline Yes & 10 & $3(1.9)$ & $7(6.1)$ & $0.294(0.074-1.162)$ & \\
\hline CEA level, $\mathrm{ng} / \mathrm{mL}$, mean $\pm \mathrm{SD}$ & $1.45 \pm 1.51$ & $1.51 \pm 1.51$ & $1.37 \pm 1.52$ & & .601 \\
\hline$\leq 2.5$ & 231 & $133(83.6)$ & $98(86.0)$ & Reference & \\
\hline$>2.5$ & 42 & $26(16.4)$ & $16(14.0)$ & $1.197(0.610-2.352)$ & \\
\hline $\mathrm{CT}$ attenuation, $\mathrm{HU}$, mean $\pm \mathrm{SD}$ & $-342.5 \pm 240.1$ & $-263.3 \pm 210.9$ & $-453.0 \pm 235.3$ & & $<.001$ \\
\hline$\leq-500$ & 92 & $30(18.9)$ & $62(54.4)$ & Reference & \\
\hline$>-500$ to -200 & 89 & $59(37.1)$ & $30(26.3)$ & $4.064(2.189-7.548)$ & $<.001$ \\
\hline$>-200$ & 92 & $70(44.0)$ & $22(19.3)$ & $6.576(3.441-12.567)$ & $<.001$ \\
\hline Size, $\mathrm{cm}$, mean $\pm \mathrm{SD}$ & $1.59 \pm 0.71$ & $1.92 \pm 0.65$ & $1.13 \pm 0.50$ & & $<.001$ \\
\hline$\leq 1$ & 74 & $12(7.5)$ & $62(54.4)$ & $0.100(0.049-0.205)$ & $<.001$ \\
\hline$>1$ to 2 & 129 & $85(53.5)$ & $44(38.6)$ & Reference & \\
\hline$>2$ to 3 & 70 & $62(39.0)$ & $8(7.0)$ & $4.012(1.764-9.121)$ & .001 \\
\hline Spiculation & & & & & $<.001$ \\
\hline No & 137 & $45(28.3)$ & $92(80.7)$ & Reference & \\
\hline Yes & 136 & $114(71.7)$ & $22(19.3)$ & $10.594(5.936-18.905)$ & \\
\hline Vascular convergence & & & & & $<.001$ \\
\hline Yes & 223 & $153(96.2)$ & $70(61.4)$ & Reference & \\
\hline No & 50 & $6(3.8)$ & $44(38.6)$ & $0.062(0.025-0.153)$ & \\
\hline Pleural tag & & & & & $<.001$ \\
\hline Yes & 150 & $126(79.2)$ & $24(21.1)$ & Reference & \\
\hline No & 123 & $33(20.8)$ & $90(78.9)$ & $0.070(0.039-0.126)$ & \\
\hline Solid proportion & & & & & $<.001$ \\
\hline 0 & 86 & $24(15.1)$ & $62(54.4)$ & $0.604(0.189-0.948)$ & $<.001$ \\
\hline$<50 \%$ & 110 & $73(45.9)$ & $37(32.5)$ & Reference & \\
\hline$\geq 50 \%$ & 77 & $62(39.0)$ & $15(13.2)$ & $6.576(3.441-12.567)$ & $<.001$ \\
\hline
\end{tabular}

$I P A$, Invasive pulmonary adenocarcinoma; $O R$, odds ratio; $C I$, confidence interval; $S D$, standard deviation; $C E A$, carcinoembryonic antigen; $C T$, computed tomography; $H U$, Hounsfield units. *Including benign ( 35 cases), atypical adenomatous hyperplasia (3 cases), adenocarcinoma in situ (18 cases), and minimally invasive adenocarcinoma (58 cases).

our model was mainly found in the low-risk cutoff points for defining a negative result, which agreed with the previous research. ${ }^{22}$

Several prediction models have been developed and validated to assess the probability of malignancy in pulmonary nodules ${ }^{22-25}$; however, the management and evaluation of SSN falls into a category that has not previously been given specific or detailed consideration. ${ }^{21,26}$ To our knowledge, this study was the first to construct a quantitative nomogram to predict the probability of IPA in patients with SSN. The previous nomograms focused only on the prognostic effects to predict the survival of patients with lung cancer. ${ }^{9,27}$ In our nomogram, the lesion size is the greatest contributor to 
TABLE 2. Logistic multivariable regression analysis of the risk of invasive adenocarcinoma

\begin{tabular}{|c|c|c|c|c|c|c|}
\hline \multirow[b]{2}{*}{ Variables } & \multicolumn{3}{|c|}{ Multivariable analysis } & \multicolumn{3}{|c|}{ Selected factors for model } \\
\hline & OR & $95 \%$ CI & $\boldsymbol{P}$ & OR & $95 \%$ CI & $\boldsymbol{P}$ \\
\hline Age, $y$ & & & .112 & & & \\
\hline$\leq 60$ & Reference & & & & & \\
\hline$>60$ & 1.742 & $0.879-3.450$ & & & & \\
\hline Family history of lung cancer & & & .515 & & & \\
\hline No & Reference & & & & & \\
\hline Yes & 0.530 & $0.078-3.582$ & & & & \\
\hline CT attenuation, $\mathrm{HU}$ & & & .318 & & & .198 \\
\hline$\leq-500$ & Reference & & & & & \\
\hline$>-500$ to -200 & 1.323 & $0.484-3.615$ & .585 & 1.690 & $0.719-3.971$ & .228 \\
\hline$>-200$ & 1.544 & $0.638-4.144$ & .685 & 1.791 & $0.892-4.145$ & .645 \\
\hline Size & & & $<.001$ & & & $<.001$ \\
\hline$\leq 1$ & 0.222 & $0.092-0.537$ & .001 & 0.214 & $0.091-0.501$ & $<.001$ \\
\hline$>1$ to 2 & Reference & & & & & \\
\hline$>2$ to 3 & 2.175 & $0.808-5.375$ & .092 & 2.175 & $0.880-5.375$ & .092 \\
\hline Spiculation & & & .003 & & & .002 \\
\hline No & Reference & & & & & \\
\hline Yes & 3.225 & $1.487-6.995$ & & 3.312 & $1.538-7.133$ & \\
\hline Vascular convergence & & & .032 & & & .032 \\
\hline Yes & Reference & & & & & \\
\hline No & 0.300 & $0.100-0.901$ & & 0.300 & $0.100-0.901$ & \\
\hline Pleural tag & & & .001 & & & .001 \\
\hline Yes & Reference & & & & & \\
\hline No & 0.281 & $0.130-0.606$ & & 0.281 & $0.130-0.606$ & \\
\hline Solid proportion & & & .531 & & & .534 \\
\hline 0 & 0.857 & $0.271-2.712$ & .794 & 0.784 & $0.248-2.479$ & .679 \\
\hline$<50 \%$ & Reference & & & & & \\
\hline$\geq 50 \%$ & 1.526 & 0.639-3.994 & .345 & 1.500 & $0.631-3.911$ & .311 \\
\hline
\end{tabular}

the risk of IPA, followed by the vascular convergence signs, pleural tag and spiculation. CT attenuation and solid proportion showed the smallest effect on the probability of IPA.

Recently, an evidence-based, prospective study of 2 highrisk screening cohorts (Pan-Canadian Early Detection of Lung Cancer Study and British Columbia Cancer Agency) found that age, sex, family history of lung cancer, emphysema, nodule size, location of the nodule, solid proportion, nodule count, and spiculation were predictors of a malignant pulmonary nodule ${ }^{22}$; however, only nodule size and solid proportion were found to be significant to the risk of IPA. ${ }^{12,14}$ Moreover, CT attenuation, vascular convergence signs, and the pleural tag were demonstrated as predictive factors of pathologic IPA for pulmonary SSN based on the limited sample size. ${ }^{12,14,28,29}$ These findings were similar to the result of our reports on IPA risk factors for SSN. We found that CT attenuation, nodule size, spiculation, vascular convergence signs, the pleural tag, and solid proportion were predictors of IPA for SSN.

Notably, the Fleischner Society published guidelines in 2013 for the management of SSNs in general practice: these included a recommendation for the use of prediction models to assess the probability of malignancy, based on expert opinions and available scientific evidence; however, overmanagement in clinical practice is common. ${ }^{30}$ In our study, $12.8 \%$ of the resected solitary SSN were found to be benign. The number of benign tumors removed in our study was lower than in previous reports: for example, one investigation found that that the tumors from $27 \%$ of patients who underwent resection for a focal pulmonary lesion were benign. ${ }^{25}$ Hence, the number of these unnecessary procedures should continue to be reduced. Moreover, for malignant pulmonary nodules, the most common classification of those that are resected is lung adenocarcinoma. ${ }^{3,4}$ The current surgery strategy for different pathologic stages of lung adenocarcinoma tends to differ, ${ }^{4,6}$ and until now, there has been no effective model to guide surgical management. Intraoperative frozen section diagnosis seems to be a helpful guide for surgical management, but it is not suitable for use in all cases. ${ }^{6}$ Therefore, a useful model for patients who are considered for surgery should be constructed by a thoracic surgeon. Our nomogram could be considered to be an important model by compensating for the deficiencies of the previous prediction models for SSN. 


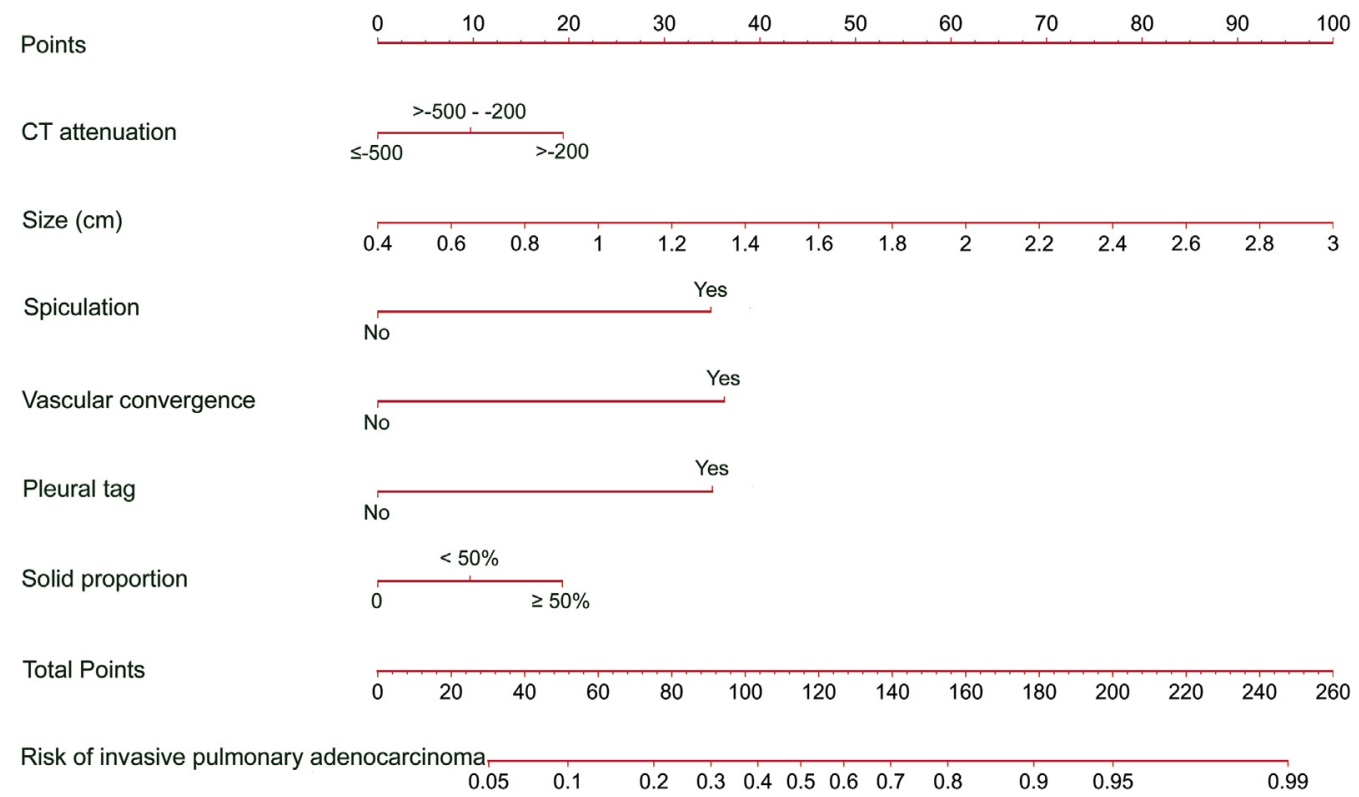

FIGURE 2. A nomogram predicting the risk of IPA for patients with solitary peripheral sub-solid nodules. The value of each of variable was given a score on the point scale axis. A total score could be easily calculated by adding each single score and, by projecting the total score to the lower total point scale, we were able to estimate the probability of IPA.

Several limitations in this study should be addressed. First, we reviewed only the records of patients who underwent resection of a solitary peripheral SSN; patients who did not undergo a resection were excluded. As a result of this selection bias, our model therefore includes patients

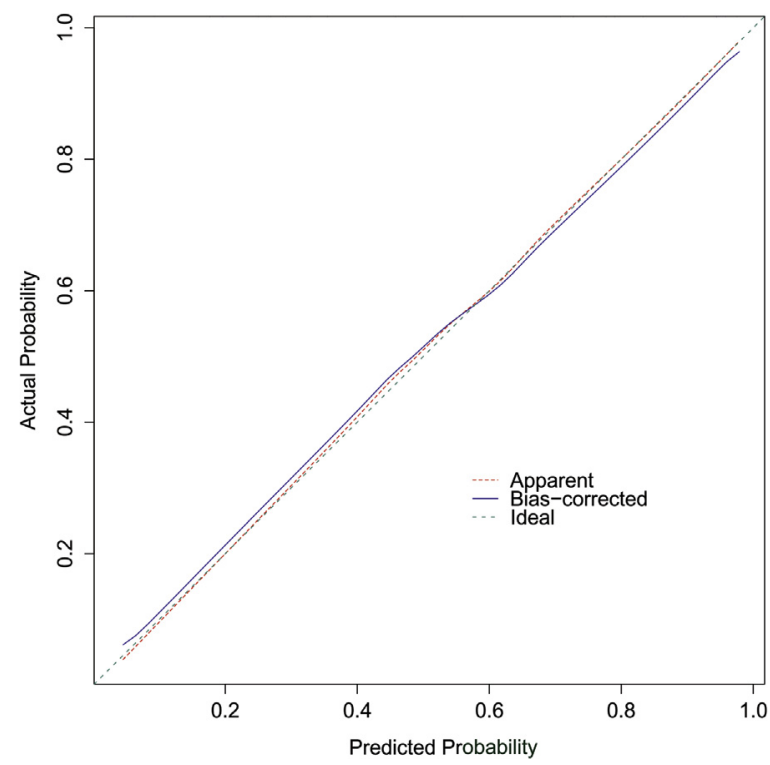

FIGURE 3. The calibration curves for the nomogram. The $x$-axis represents the nomogram-predicted probability and y-axis represents the actual probability of invasive adenocarcinoma. Perfect prediction would correspond to the $45^{\circ}$ green dashed line. The red dotted line represents the entire cohort ( $\mathrm{n}=273)$, and the blue solid line is bias-corrected by bootstrapping ( $\mathrm{B}=1000$ repetitions), indicating observed nomogram performance. with a greater probability of having a malignancy. If all patients who have ever had a solitary peripheral SSN were included, the actual area under the receiver operating characteristic curve would be more accurate. ${ }^{25}$ Second, although internal validation of the model yielded optimal discrimination and excellent calibration, the generalizability of this nomogram still requires external validation with the use of additional databases, particularly from other countries, considering the differences in epidemiology and clinical behavior that exist between ethnic groups. ${ }^{31}$ Third, our prediction model was constructed retrospectively, and only a small proportion of the patients had a positron emission tomography examination; therefore, it failed to incorporate these results and some recognized molecular factors, such as mutations in EGFR, KRAS, $A L K$, or HER2. ${ }^{32}$ Further data collection, wider geographic recruitment, and incorporation of positron emission tomography results and some molecular factors could improve this model for future use.

TABLE 3. Classification accuracy for prediction of invasive pulmonary adenocarcinoma at different risk cutoff points for the model

\begin{tabular}{lccccc}
\hline $\begin{array}{l}\text { Risk score } \\
\text { threshold }\end{array}$ & $\begin{array}{c}\text { Sensitivity } \\
(\%)\end{array}$ & $\begin{array}{c}\text { Specificity } \\
(\%)\end{array}$ & $\begin{array}{c}\text { PPV } \\
(\%)\end{array}$ & $\begin{array}{c}\text { NPV } \\
(\%)\end{array}$ & $\begin{array}{c}\text { Accuracy } \\
(\%)\end{array}$ \\
\hline$\geq 5 \%$ & 97.5 & 28.1 & 65.4 & 88.9 & 68.5 \\
$\geq 30 \%$ & 91.2 & 68.4 & 80.1 & 84.8 & 81.7 \\
$\geq 50 \%$ & 86.2 & 78.9 & 85.1 & 80.4 & 83.2 \\
$\geq 58 \%$ & 81.8 & 81.5 & 86.1 & 76.2 & 81.7 \\
$\geq 65 \%$ & 78.6 & 82.5 & 86.2 & 73.4 & 80.2 \\
\hline
\end{tabular}

$P P V$, Positive predictive value; $N P V$, negative predictive value. 


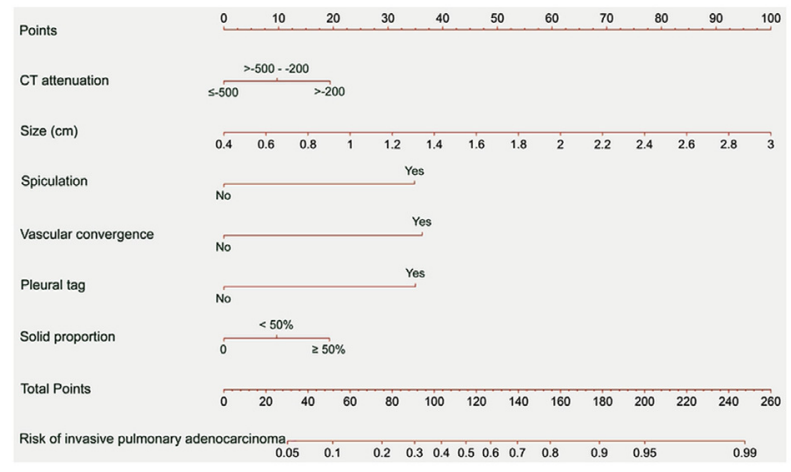

VIDEO 1. A nomogram for predicting the risk of invasive pulmonary adenocarcinoma for patients with solitary peripheral subsolid nodules. The current surgery strategy for preinvasive and invasive pulmonary adenocarcinoma tends to differ, and until now, there has been no effective model to guide surgical management. We developed a nomogram that can predict the risk of invasive pulmonary adenocarcinoma for patients with a solitary peripheral subsolid nodule. In our nomogram, the lesion size is the greatest contributor to the risk of invasive pulmonary adenocarcinoma (100 points), followed by the vascular convergence signs (36.5 points), pleural tag (35 points), and spiculation (35 points). Computed tomography (CT) attenuation (19 points) and solid proportion (19 points) showed the smallest effect on the probability of invasive pulmonary adenocarcinoma. For example, a 64-year-old man with a $1.7-\mathrm{cm}$ pure ground-glass nodule in the right upper lobe. The CT attenuation is -645 , we only see the vascular convergence signs in the nodule. The total points of this patient is 86.5 , the risk of invasive pulmonary adenocarcinoma is about $26 \%$. The pathologic specimens were diagnosed as minimally invasive adenocarcinoma; sublobar resection may be acceptable. This patient is a 72-year-old man with a 3.0-cm nodule in the left upper lobe. The CT attenuation is -400 and solid proportion is more than $50 \%$, we can see vascular convergence signs and spiculation in the nodule. The total points of this patient is about 200.5, the risk of invasive pulmonary adenocarcinoma is more than $95 \%$. The pathologic specimens were diagnosed as invasive adenocarcinoma, which means it is potentially amenable to treatment with the standard lobectomy and the scope of lymph node dissection. Importantly, validation via use of the bootstrap resampling revealed optimal discrimination and calibration, indicating that the nomogram may have clinical utility. Our nomogram has the potential to assist clinicians in making treatment recommendations for patient with a solitary peripheral subsolid nodule. Video available at: http://www.jtcvsonline.org/article/S0022-5223(16)31395-2/addons.

In conclusion, we have developed and internally validated a novel nomogram for predicting the risk of IPA for patients with a solitary peripheral SSN in a surgical population. The nomogram is easy to use, is highly accurate, and exhibits excellent calibration. This nomogram might help clinicians to make individualized predictions of each patient's probability of IPA and to improve treatment recommendations for patients with a solitary peripheral SSN (Video 1).

\section{Conflict of Interest Statement}

Authors have nothing to disclose with regard to commercial support.
The authors acknowledge the Professor Yi Shen (Department of Epidemiological and Health Statistics, Zhejiang University) for help with the manuscript.

\section{References}

1. Kanne JP, Jensen LE, Mohammed TL, Kirsch J, Amorosa JK, Brown K, et al. ACR appropriateness Criteria ${ }^{\circledR}$ Radiographically detected solitary pulmonary nodule. J Thorac Imaging. 2013;28:W1-3.

2. Callister ME, Baldwin DR, Akram AR, Barnard S, Cane P, Draffan J, et al. British thoracic society guidelines for the investigation and management of pulmonary nodules. Thorax. 2015;70(suppl 2):ii1-54.

3. Zhao H, Marshall HM, Yang IA, Bowman RV, Ayres J, Crossin J, et al. Screen-detected subsolid pulmonary nodules: long-term follow-up and application of the PanCan lung cancer risk prediction model. $\mathrm{Br} J$ Radiol. 2016;89:20160016.

4. Kodama K, Higashiyama M, Takami K, Oda K, Okami J, Maeda J, et al. Treatment strategy for patients with small peripheral lung lesion(s): intermediate-term results of prospective study. Eur J Cardiothorac Surg. 2008; 34:1068-74.

5. Travis WD, Brambilla E, Noguchi M, Nicholson AG, Geisinger KR, Yatabe Y, et al. International Association for the Study of lung Cancer/ American Thoracic Society/European Respiratory Society: international multidisciplinary classification of lung adenocarcinoma. J Thorac Oncol. 2011;6:244-85.

6. Liu S, Wang R, Zhang Y, Li Y, Cheng C, Pan Y, et al. Precise diagnosis of intraoperative frozen section is an effective method to guide resection strategy for peripheral small-sized lung adenocarcinoma. J Clin Oncol. 2016; 34:307-13.

7. Van Schil PE, Asamura H, Rusch VW, Mitsudomi T, Tsuboi M, Brambilla E, et al. Surgical implications of the new IASLC/ATS/ERS adenocarcinoma classification. Eur Respir J. 2012;39:478-86.

8. Zhang Y, Sun Y, Xiang J, Zhang Y, Hu H, Chen H. A clinicopathologic prediction model for postoperative recurrence in stage la non-small cell lung cancer. J Thorac Cardiovasc Surg. 2014;148:1193-9.

9. Liang W, Zhang L, Jiang G, Wang Q, Liu L, Liu D, et al. Development and validation of a nomogram for predicting survival in patients with resected non-small-cell lung cancer. J Clin Oncol. 2015;33:861-9.

10. Nuorti JP, Butler JC, Farley MM, Harrison LH, McGeer A, Kolczak MS, et al. Cigarette smoking and invasive pneumococcal disease. Active Bacterial Core Surveillance Team. N Engl J Med. 2000;342:681-9.

11. Wood DE, Eapen GA, Ettinger DS, Hou L, Jackman D, Kazerooni E, et al. Lung cancer screening. J Natl Compr Canc Netw. 2012;10:240-65.

12. Liang J, Xu XQ, Xu H, Yuan M, Zhang W, Shi ZF, et al. Using the CT features to differentiate invasive pulmonary adenocarcinoma from pre-invasive lesion appearing as pure or mixed ground-glass nodules. Br J Radiol. 2015;88:20140811.

13. Hu H, Wang Q, Tang H, Xiong L, Lin Q. Multi-slice computed tomography characteristics of solitary pulmonary ground-glass nodules: differences between malignant and benign. Thorac Cancer. 2016;7:80-7.

14. Eguchi T, Yoshizawa A, Kawakami S, Kumeda H, Umesaki T, Agatsuma H, et al. Tumor size and computed tomography attenuation of pulmonary pure groundglass nodules are useful for predicting pathological invasiveness. PLoS One. 2014;9:e97867.

15. Karlo CA, Kou L, Di Paolo PL, Kattan MW, Motzer RJ, Russo P, et al. Renal cell carcinoma: a nomogram for the CT imaging inclusive prediction of indolent, nonclear cell renal cortical tumours. Eur J Cancer. 2016;59:57-64.

16. Iasonos A, Schrag D, Raj GV, Panageas KS. How to build and interpret a nomogram for cancer prognosis. J Clin Oncol. 2008;26:1364-70.

17. Bandos AI, Rockette HE, Song T, Gur D. Area under the free-response ROC curve (FROC) and a related summary index. Biometrics. 2009;65:247-56.

18. Harrell FE Jr, Lee KL, Mark DB. Multivariable prognostic models: issues in developing models, evaluating assumptions and adequacy, and measuring and reducing errors. Stat Med. 1996;15:361-87.

19. Gould MK, Donington J, Lynch WR, Mazzone PJ, Midthun DE, Naidich DP, et al. Evaluation of individuals with pulmonary nodules: when is it lung cancer? Diagnosis and management of lung cancer, 3rd ed: American College of Chest Physicians evidence-based clinical practice guidelines. Chest. 2013;143(5 suppl):e93S-120S.

20. Frank E, Harrell Jr. rms: Regression Modeling Strategies. Package rms version 4.3-0. Available at: http://www.r-project.org. Accessed February 20, 2016. 
21. Naidich DP, Bankier AA, MacMahon H, Schaefer-Prokop CM, Pistolesi M, Goo JM, et al. Recommendations for the management of subsolid pulmonary nodules detected at CT: a statement from the Fleischner Society. Radiology. 2013;266:304-17.

22. McWilliams A, Tammemagi MC, Mayo JR, Roberts H, Liu G, Soghrati K, et al. Probability of cancer in pulmonary nodules detected on first screening CT. $N$ Engl J Med. 2013;369:910-9.

23. Swensen SJ, Silverstein MD, Ilstrup DM, Schleck CD, Edell ES. The probability of malignancy in solitary pulmonary nodules. Application to small radiologically indeterminate nodules. Arch Intern Med. 1997;157:849-55.

24. Gould MK, Ananth L, Barnett PG. A clinical model to estimate the pretest probability of lung cancer in patients with solitary pulmonary nodules. Chest. 2007; 131:383-8.

25. Isbell JM, Deppen S, Putnam JB Jr, Nesbitt JC, Lambright ES, Dawes A, et al. Existing general population models inaccurately predict lung cancer risk in patients referred for surgical evaluation. Ann Thorac Surg. 2011;91: 227-33.

26. MacMahon H. Compliance with Fleischner Society guidelines for management of lung nodules: lessons and opportunities. Radiology. 2010;255:14-5.

27. Song SH, Ahn JH, Lee HY, Lee G, Choi JY, Kang J, et al. Prognostic impact of nomogram based on whole tumour size, tumour disappearance ratio on CT and SUVmax on PET in lung adenocarcinoma. Eur Radiol. 2016;26: $1538-46$.
28. Son JY, Lee HY, Lee KS, Kim JH, Han J, Jeong JY, et al. Quantitative CT analysis of pulmonary ground-glass opacity nodules for the distinction of invasive adenocarcinoma from pre-invasive or minimally invasive adenocarcinoma. PLoS One. 2014;9:e104066.

29. Cohen JG, Reymond E, Lederlin M, Medici M, Lantuejoul S, Laurent F, et al Differentiating pre- and minimally invasive from invasive adenocarcinoma using CT-features in persistent pulmonary part-solid nodules in Caucasian patients. Eur J Radiol. 2015;84:738-44.

30. Mets OM, de Jong PA, Chung K, Lammers JJ, van Ginneken B, Schaefer Prokop CM. Fleischner recommendations for the management of subsolid pulmonary nodules: high awareness but limited conformance-a survey study Eur Radiol. March 5, 2016 [Epub ahead of print].

31. Zhou W, Christiani DC. East meets West: ethnic differences in epidemiology and clinical behaviors of lung cancer between East Asians and Caucasians. Chin J Cancer. 2011;30:287-92.

32. Kobayashi Y, Mitsudomi T, Sakao Y, Yatabe Y. Genetic features of pulmonary adenocarcinoma presenting with ground-glass nodules: the differences between nodules with and without growth. Ann Oncol. 2015;26:156-61.

Key Words: solitary pulmonary sub-solid nodules, invasive adenocarcinoma, risk factors, predictive model, nomogram

Readers who found these articles interesting may also like to read the following papers found in recent and future issues of our sister publications, Seminars in Thoracic and Cardiovascular Surgery and Operative Techniques in Thoracic and Cardiovascular Surgery!

\section{Thoracic: Thoracic Oncology}

News and Views: Computer-Aided Nodule Assessment and Risk Yield Risk Management of Adenocarcinoma: The Future of Imaging? Finbar Foley. Semin Thoracic Surg 2016; 28:120-126.

Original Submission: Robotic Esophagectomy for Cancer: Early Results and Lessons Learned. Robert J. Cerfolio. Semin Thoracic Surg 2016; 28:160-169.

Editorial Commentary: Improving Quality: When Surgeons Take the Bit Between the Teeth, Patients Win! Katie S. Nason. Semin Thoracic Surg 2016: 28:170-171.

Original Submission: Second Primary Lung Cancers Demonstrate Better Survival with Surgery than Radiation. Emanuela Taioli. Semin Thoracic Surg 2016; 28:195-200.

Editorial Commentary: Surgery is the Optimum Local Therapeutic Modality for Second Primary Lung Cancer. Jeffrey L. Port. Semin Thoracic Surg 2016; 28:201-202.

Discussions in Cardiothoracic Treatment and Care: The Next Generation of Mesothelioma Surgeons. Harvey I. Pass. Semin Thoracic Surg 2016; 28:203-220.

Original Submission: The 3-Hole Minimally Invasive Esophagectomy: A Safe Procedure Following Neoadjuvant Chemotherapy and Radiation. Rona Spector. Semin Thoracic Surg 2015; 27: 205-215.

Editorial Commentary: With Minimally Invasive Esophagecomty, Thoracic Surgeons Must Avoid Falling Into the Same Trap Again. Ng Thomas. Semin Thoracic Surg 2015; 27:216-217.

Original Submission: Maximal Oxygen Uptake - Risk Predictor of NSCLC Resection with Comorbid Emphysema: Lessons from NETT. Ian Makey. Semin Thoracic Surg 2015; 27:225-224.

Editorial Commentary: How Can the NETT Provide Guidance in Risk Stratification for Patients with Severe Emphysema and Early Stage NSCLC? Michael Hsin. Semin Thoracic Surg 2015; 27:232-233.

State of the Art: Induction Therapy for Mesothelioma. Isabelle Schmitt-Opitz. Semin Thoracic Surg 2015; 27:240-249. 
APPENDIX 1. RELATED COMPUTERIZED

PROGRAMS FOR NOMOGRAM WITH R

library (rms)

Set the prarmeters

ddist $<$-datadist $($ Size,......$)$

options (datadist $=$ 'ddist')

For Logistic Regression Model

$\mathrm{f}<-\operatorname{lrm}(\mathrm{y} \sim$ Size $+\ldots . ., \mathrm{x}=\mathrm{T}, \mathrm{y}=\mathrm{T})$
For Nomogram

nom <-nomogram(f,fun $=$ plogis, fun.at $=\mathrm{c}(.001, .01, .05$, $\operatorname{seq}(.1, .9, \mathrm{by}=.1), .95, .99, .999), \mathrm{lp}=\mathrm{F}$, funlabel="Risk of invasive pulmonary adenocarcinoma")

plot (nom)

For Resampling Validation of Nomogram

validate (f, method = "boot," B =1000, $\mathrm{dxy}=\mathrm{T}$ )

For Calibration Curve

cal $<$-calibrate $(f$, method $=$ "boot," B = 1000)

plot (cal) 